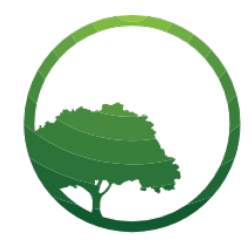

Business \& Social Science IJRBS

\section{Research in Business and Social Science}

IJRBS Vol 6 No 5, Special Issue, ISSN: 2147-4478

Contents available at www.ssbfnet.com/ojs

http://dx.doi.org/10.20525/ijrbs.v6i5.706

\title{
The impact of investment projects in the local economic development in post-conflict countries
}

\section{Albana Gashi Zhinipotoku}

Riinvest College, Prishtina, Kosova

\section{Bujar Pira}

University of Applied Sciences in Ferizaj, Kosova

\begin{abstract}
This study will contribute towards the evaluation of the effects of the investment project "Supporting production businesses", in Shtime, as part of the local economic development strategy. For the study were used primary data (Interview) and secondary data (official document and relevant reports) based on identified indicators, as: 1)Type of support (value of money, number of donation, surface offered on $\mathrm{m2}$, location, number of training offered); 2) number of businesses, number new job created, number of taxpayers, number of new investment and 3) number of new products, new market, new technology, increase in turnover / profit, or changes in business organization. As a result of the support provided, these enterprises continue to develop their business successfully. The project has had a positive impact on local economic development in the municipality of Shtime, contributing to employment growth, increasing the number of taxpayers as well as improving the business structure in favour of processing enterprises. Furthermore, as a result of this project, these enterprises have recorded an increase in turnover and profit, as well as expanding their market with new products. This research shows the impact of the public investment in local economic development in particular with the small production companies.
\end{abstract}

Key words: Local economic development, Employment, Evaluation, Shtime.

JEL classification: $010, R 10$

\section{Introduction}

As an integral part of the strategic process at the national level, Local Economic Development (LED) enables creating a better and competitive environment at local level, as well. LED is the process where local communities (public, businesses and non-governmental organizations) work 
towards achieving a sustainable economic development and enables the growth of employment, welfare and quality of life for all (World Bank, 2009).

Local economic development is one of the most important areas to increase the quality of life for citizens and creating a favourable environment for business development (Riinvest, 2002).

Changes in administrative and political culture in Kosovo municipalities, reflect a different situation of local economic development in Kosovo, especially in the post war period in 1999. The different municipality assisted by different international organizations which have implemented different projects in local economic development field (UNDP, 2005).

In this regard, since 2002 RIINVEST Institute in cooperation with the Open Society Institute/Local Government Initiative (OSI / LGI) based in Budapest, has implemented the DELTA (Developing Enterprises Locally through Actions and Alliances), implemented in three phases, with the aim on capacity building of municipal officials towards developing strategies for local economic development. The beneficiaries of the project were 17 municipalities of Kosovo, as Istok, Kaçanik, Klina, Prizren, Podujevo, Viti and Vushtrria (phase 1), Peja Lipjani, Gjilan, Ferizaj and Drenas (phase 2) and Dragash, Kamenica Malisheva, Obiliq and Shtime (third phase).

The main goal of the project was to enable beneficiary municipalities in creating favourable conditions for development of small and medium enterprises (SMEs), which would contribute to local economic development.

As a continuation, Riinvest has implemented also the project regarding the establishment of local government capacity for monitoring, implementation and evaluation of strategies in five municipalities beneficiary of the third phase of the project DELTA, as in Shtime, Kamenica, Malishevé, Dragash and Obilic, while outcome of this project was the preparation of the five evaluation reports on the implementation of LED strategies of these municipalities

Based on these reports, the municipality of Shtime was one of the municipality which had reached the highest percentage of implementation of the LED strategy, developed with DELTA Project.

Therefore, until that moment when the project was being developed, the municipality has managed to realize $83 \%$ of the strategy, while the time for complete fulfilment of the identified objectives according strategic planning had not yet expired (RIINVEST, 2009).

Identification of feasible projects within LED strategy, made the strategy document of Shtime municipality more easy to implement, among which was also the project "Supporting production businesses".

The aim of this study is to evaluate the effects of the project "Supporting production businesses", in Shtime, based on the outcomes that the municipality has identified the with the local economic development strategy for the period 2007-2010.

\section{Literature review}

Concepts of assessment has changed with the changing of socio-political and social environment. In early, assessment has been more informal, ad-hoc and less rigorous, which has served more for assessment of programs needs by helping people individually to make strategic decisions. Today, the applicability of evaluation contributes to all management functions and at all levels of communication. 
Nowadays, the assessment relates primarily to the object, not the subject or personal individual needs, and to achieve this requires a systematic planning and adequate resources. The assessment is designed and compiled so that the results of the assessment can be used by as many people and serve the needs of a large number of organizations (Andrews, 1983).

Monitoring and evaluation are essential aspects of a good management of projects, programs or strategies at all levels, national, regional and local (The Global Fund, 2009). While monitoring the performance follows a strategy, program or project during its implementation process, evaluation measures the effects after implementation. Monitoring and evaluation are closely related and do not replace but complement each other, and together they help to plan and manage change, and also to follow the progress, results and possible impacts in the future. (Cunliffe, 2010).

The data generated from monitoring are essential for a successful evaluation. Monitoring is a continuous process that follows the progress of activities and other procedures of a project, program, policy, strategy, while utilizing data collected to inform management consistently related problems and possible actions for improvement. On the other hand, the assessment is periodic, and focus on results achieved in accordance with used resources in order to provides managers with strategy and policy options policies. (UNFPA, 2004).

Monitoring and evaluation are necessary management tools for project management. Establishing and implementing an adequate system for monitoring and evaluation, requires knowledge about the progress of a project and the interaction between different projects, project elements or partners involved in projects (IFAD, 2002).

In literature there are different definitions of evaluation which are similar but differ depending on the context, purpose and approach. In this regard, Rossi and Freeman (1993), with the evaluation means application of research procedures for assessing the concept, design, implementation and usability of programs and projects.

Steel (1970) fro other side, mention that the meaning of evaluation is often overlooked. The author says, "Evaluation must be purposeful and not done just for its own sake. Evaluation is the process of determining the extent to which objectives have been attained" (Steel, 1970, pg. 1). Evaluation is an important tool that your organization can use to demonstrate its accountability, improve its performance, increase its abilities for obtaining funds or future planning, and fulfil the organizational objectives (Zarinpoush, 2006).

"Before evaluating a programme, the reasons for the evaluation should be clearly defined, otherwise if the purpose is not clear, there is a risk that the evaluation will focus on the wrong concerns, draw the wrong conclusions and provide recommendations which will not be useful for the intended users of evaluation results" (UNFPA, 2004).

The clearer is the purpose of the evaluation, the most obvious and easily feasible is the process of evaluation.

The purpose of the evaluation is to provide information to assist in decision making (Zarinpoush, 2006).

In the broader sense, the purpose of evaluation means measuring the performance of activities or services, measuring the performance of human resources in general within an organization (governmental, public or private) or the performance of project, program or strategy team. According to Trochim (2006), the overall goal of the evaluation is to provide useful feedback (feedback) to a wide audience including sponsors, donors, clients, administrators, staff and other stakeholders on relevant topics of interest that helps in decision making. 
Today in the world of evaluation, is very well developed concept of "system of evaluation" (Leeuw\&Furubo, 2008).

In this regard, in their article they cite these types of evaluation systems, which are typically used in the western world, which are:

- System of performance monitoring;

- System of performance of audit, inspection and supervision;

- Quasi-experimental system of evaluation and for "evidence- based policy"

- System of Evaluation and Accreditation and

- System of Evaluation and Monitoring"

So, evaluation is usually done for a specific purpose and is a process of making questions on a particular issue, which contributes to the process of data collection and analysis, from deriving answers to the questions asked (Weis, Berger\&Hatcher, 2008).

According to many authors, the evaluation is a particular area of research strategies in the field of social sciences.

Definition and the purpose of evaluation guide evaluators in applying different evaluation approach.

"For each type of evaluation have been developed adequate evaluation approach which best suit the purpose of evaluation"(Roberts\&Couts, 2007, f. 3).

Based on the job of Stecher\&Davis (1987) and Popham (1993) on evaluation, Roberts dhe Coutts, has presented a paper on "APEN National Forum" conference, with the topic on monitoring, evaluation and reporting by presenting the evaluation approaches, as below:

- Experimental approach - which is based on experimental work, treating a program or project based on some special units and then measuring comparative effects between treated units versus untreated units of the program or project;

- Goal oriented approach - which assesses the achievements in order to meet the goal of a program / project;

- Approach focused on decision - this approach is characterized with the work of Stufflebeam, which has developed the "CIPP (Context, Input, Process and Product evaluation)" model (Roberts dhe Coutts, 1993, f.4), according to which, the Context of a program $(C)$, Input $(I N)$, Process $(P)$ for developing the program and the product $(P)$ derived as a result of the program, in the begging need to evaluate separately to to see their individual effects to the final result and then evaluation of their effects as related;

- User-oriented approaches - in this case is presented the work of Patton, (1986 on Roberts and Coutts, 1993, pg.5), which was concerned with the fact that the results arising from the evaluation, in most cases were not concerned. For this reason he laid emphasis on the use of evaluation results, that the evaluation process should be developed so that the results arising from that assessment could be used, i.e to be implemented for longer period; 
- Stakeholder - oriented approach - characterized with the work of Robert Stake and Carol Weiss (1983, on Roberts and Coutts, 1993), who emphasize the fact that if we want the evaluation to be more successful then the stakeholders should be included both in the design phase of the evaluation process and during the collection of data needed for evaluation;

- Approach based on responsibility and participation - based on Guba\&Lincoln (1989) Model, which means a partnership of all stakeholders during the evaluation process, as in the planning stage of evaluation, assessment activities that needs to be undertaken as well as on the evaluation process.

Methodology is a group of analytical methods, procedures and techniques used to collect and analyse relevant information for the evaluation of a strategy / program / project or certain components and their activities (UNFPA, 2004).

Evaluation process leads the process of collection of data needed for evaluation, from which emerge the results. Depending on the nature of the project, a different evaluation methodologies are going to be used. In general, there are three groups of methods that apply for collection of data, as: generally fall into three groups:

1. Quantitative Method - means collecting and analysing of numerical data, and the results derives for evaluations are described in numerical, percentages or level of improvement, meeting the goals of the program/project, respectively;

2. Qualitative Method - means collecting, analysing non-numerical data, and evaluation results are expressed in terms of descriptive reports (narrative). Qualitative methods usually find answers to case studies, developed with stakeholders of a program or project, through which develop events according to personal experiences of each party participating in the program, or project (McDavid, 2005);

3. Mixed Method - as a combination of quantitative and qualitative methods, as one of the most common methods in the evaluation process, collected from primary sources (eg field interviews) and secondary sources (existing documents and reports).

Role of Evaluator through evaluation process is to engage more stakeholders and to secure that the process and the results of the evaluation are useful for those how are responsible for improving or evaluation of one program/project or strategy. An evaluator, first of all must have education, skills and appropriate experience for evaluation.

He must demonstrate multicultural skills and use different evaluation strategies appropriate for certain countries in accordance with the culture of the country. Among other things, the evaluator must know their limitations and disadvantages of their abilities and to keep up with new trends in the field of evaluation.

American Evaluation Association (AEA, 2007) to promote ethical practices in the evaluation has also developed evaluation principles, which are:

a) Systematic Inquiry: Evaluators conduct systematic, data-based inquiries;

b) Competence: Evaluators must offer / provide competent performance (work) competent to stakeholders; 
c) Integrity / Honesty: Evaluators display honesty and integrity in their own behaviour, and attempt to ensure the honesty and integrity of the entire evaluation process;

d) spect for people: Evaluators respect the security, dignity and self-worth of respondents, program participants, clients, and other evaluation stakeholders;

e) Responsibility for the general welfare - Evaluators articulate and take into account the diversity / variety of values and general public interests" (AEA, 2007).

The term strategy has a very wide use which is used for various purposes, but generally means a set of goals, objectives, programs and projects which should be achieved within a certain period of time. Strategy is a guide to the organization, business, government, municipality or city that wants to move towards a period of time, taking into account numerous factors that influence whether they positive or negative.

Besides designing or developing the strategies, important stages are also monitoring and evaluation phases of which depends the success of the strategy.

Monitoring and evaluation play a crucial role in the strategic planning process, namely for the fact that:

- Increase transparency and the accountability;

- Increase the degree for success of the strategy implementation;

- Make room for better organization of the partnership;

- Rational usage of resources".

(Mustafa, 2009).

There are certain criteria to be applied during the evaluation process of strategies, which is mentioned in any literature and by any author, listed as below (Rumelt, 2000). :

- Consistency: Strategies should be consistent and have a logical connection between objectives and policies;

- Adaption: Strategies should serve as a response to external factors and changes that come from the external environment;

- Advantage: Strategies should provide a competitive advantage in certain areas;

- Rationale: Strategies should neither have excessive amounts of resource utilization nor deficient, i.e must have sufficient quantity available".

On the other hand, programs are designed to achieve a strategic objective which itself includes a number of projects and evaluation process project includes the steps necessary to measure performance of the project in accordance with the purpose / objective of the strategic set.

Objectives should be most specific, measurable and defined in time, which helps in determining indicators as a measured instrument for effects of the project and the impact of project outcomes, as well as participating stakeholders / beneficiaries of the project.

In theory there are several approaches to evaluate whether strategies, programs or projects, arising from the purpose of evaluation.

Weis, Berger\&Hatcher (2008), $n$ their guidelines for the assessment of strategies, describes two types of assessment, as: 
1. Process evaluation, conducted to assess whether a strategy is being implemented as planned and whether it is reaching its intended population. Specifically, process evaluation is a sort of quality assurance that focuses on the implementation itself and, as such, is a critical component in improving the practices that operationalize strategies.

2. Outcome evaluation, or impact evaluation, is conducted to learn whether you achieved the intended outcomes of your strategy. Outcome evaluation can tell us if the strategy was effective.

While the strategy consists of a number of programs, which affect the implementation of strategies, then the results from the evaluation of the programs are a result for the strategy evaluation.

In this regard, I will mention three types of program evaluation, describes by Carter McNamara (2002), and which are commonly used for evaluation of programs:

1. Goals-Based Evaluation - are evaluating the extent to which programs are meeting predetermined goals or objectives

2. Process-based evaluations are geared to fully understanding how a program works -- how does it produce that results that it does

3. Outcomes-Based Evaluation - this type of evaluation are usually used from nongovernmental organizations and donors / funders.

Evaluation of the programs described as management tool, which usually aims to determine relevance, efficiency, effectiveness, impact and sustainability of a program or project that comes out of that program, while the main objectives for the evaluation of a given program, and are intended:

- to inform decision makers about the actions, policies and strategies related to those programs;

- to demonstrate readiness (responsibility towards cost, decisions, reporting, etc.) for decision makers (UNFPA, 2004).

On the other hand, project evaluation informs us about the progress, success and effectiveness of the project, gives instructions for improvement, and provide information for existing or planned project (Zarinpoush, 2006).

While the project is designed in order to meet a goal and objectives of the goal, the evaluation process includes the necessary steps to measure performance of the project in accordance with the project goal.

In this regard, the objectives should be identified following the SMART techniques (Top Achievement, 2015)

Only for the objectives identified as SMART as possible, can be easily identified indicators measuring the achievement of that objective, followed with the easier process for evaluation.

Developing of a good plan for evaluation, with key evaluation elements, effect on the successful development of the evaluation process of the strategy, program or project.

\section{Research and Methodology}

The research conducted in the framework of the master dissertation deals with a case study as a methodological tool for the evaluation of a real project, namely the "Supporting manufacturing 
businesses", the project that was identified with the strategy for Local Economic Development of Shtime municipality.

Based on the purpose of the assessment, which is the measurement of the effects of the named project, based on the outcomes identified in the strategy of the Municipality of Shtime, the research questions for assessment are defined, described as followed:

1. What kind of support the Shtime municipality provided to businesses and other stakeholders and how effective has it been for businesses?

2. What has been the effect of this project on local economic development of Shtime?

3. What changes are observed in structure of the business in the municipality of Shtime enterprise as a result of this project?

While indicators as key instruments for a good evaluation process for the concrete project are as follows:

- type/role of support (value of money, number of donations, offered surface in m2, location, number of training offered for the benefited business);

- number of business, number of new jobs created, number of new taxpayers, number of new investments;

- number of new products, number of new markets, new technology, increased turnover or profit, changes in business organization.

Case study as research methodology refers to the collection and presentation of detailed information related to small groups or with special interest, as well as the conclusions drawn on specific issues.

In our case, the collection of data needed for assessment of the project, based on the indicators defined, is enabled through the use as primary data (interviews) and secondary data (official documents and reports relevant to the assessment).

Interviews were conducted with three interested groups,

1. Interviews with processing company;

2. Interviews with municipal officials;

3. Interviews with donors

Secondary data, in other side, obtained from official records in municipality, helped us to gain information regarding the effects that this project had to change the structure of the businesses in the municipality.

It was used the Evaluation report of the European Commission, as the financier of the project to show their expectations of the project and the Riinvest evaluation report on the implementation of the LED strategies, which report contains information about the degree of implementation of the strategy in general, focused more on objective and goal of the strategy contributed on concrete project. 


\section{Results and discussions}

The project "Supporting the Production Business", is considered as a necessary project by the LED teams of the Shtime municipality who have drafted a strategy for Local Economic Development, with the full support of the mayor municipality, as a project that will affect the creation of a better environment for businesses, and as a project that will increase the welfare of the local community, specifically in Shtime municipality, but also in Kosovo in general (Çerkini, 2010).

Results based approach is used to assess the effects of this project, which approach, according to the literature is commonly used approach for project evaluation.

The results for the interviews shows that, all 17 surveyed businesses are family businesses, two of them owned from women, while the majority (15 businesses) are led by men.

Being production as the main activity of these businesses, on the other hand their main production activity was different, as: growth and processing of sheep, goats and other livestock products; than fisheries, poultry feed production, production / cultivation new vegetables (tomatoes, peppers, salads, cucumbers, etc.), production and packaging of honey, hazelnut cultivation, processing of wood products (bedrooms, tables, etc.), then engraving/etching windscreen, installation irrigation system and steelworker.

Most of these businesses, sell their products on green market, small stores, or even to individuals /families in the village or district where they live and work.

It is worth mentioning that one of the producers did the export of its products. His business deals with sheep and goats, a company which has concluded a contract for sale, with restaurants not only in Kosovo but also in Albania, resulting in increase revenue $(30 \%)$ and profit $(20 \%)$ of the company (Mujota, 2011).

The other example is the company deals with the cultivations of hazelnut, which plan to star with export in years 2011 (Qorolli, 2010). Moreover, while this company won donation in year 2008, and the plantation of hazelnut require 2 year (the period from planning, growing and harvesting), in this regard the owner planed 1 ha with hazelnut, from which he expected to harvest 3 ton of hazelnut. Based on their gained information, he said the cultivating hazelnut is very profitable while costs for planting hazelnuts are very small and their cultivation process is simple and easy, in other side the selling cost goes from 3 euro on a wholesale market and 5-6 euro on retail sale (Qorolli, 2010). 
Table 1. Quantitative indicators for the evaluation of the project "Support of Production Businesses"

\begin{tabular}{|l|l|l|}
\hline Indicators & $\#-€-\%$ & Source \\
\hline Number of donation provided & 24 & Beneficiary business, Municipality \\
\hline Number of businesses interviewed & 17 & Beneficiary business \\
\hline The value of donations & $108.830 €$ & Beneficiary business \\
\hline Number of training & 3 & Beneficiary business \\
\hline The number of new employees hired & 50 & Beneficiary business \\
\hline Increasing the number of taxpayers & $30 \%$ & Municipality \\
\hline Investments in new products & 5 & Beneficiary business \\
\hline Investment in technology & 5 & Beneficiary business \\
\hline Expanding into new markets & 5 & Beneficiary business \\
\hline Increased profit & $30 \%$ & Beneficiary business \\
\hline Increased turnover & $50 \%$ & Beneficiary business \\
\hline Reducing costs & $15 \%$ & Beneficiary business \\
\hline Increased production & $40 \%$ & Beneficiary business \\
\hline
\end{tabular}

Source: Own calculations based on the data collected

The Table 1 shows the quantitative indicators derived from the interviews, in order to see in visual way the effects of provided support.

This table is generated according to the processing of data obtained from interviews, from which we can say that the introduction of offered equipment/machinery for these enterprises has increased profits (30\%) and increase circulation (50\%) as result of lower production cost (15\%) and increase production by $30 \%$ (Gashi, 2011).

While the provision of equipment has increased production, it has also resulted in increasing the number of employees by 50 new job was created (including those seasonal). To be more specific, 38 was the total number of employees for all 17 beneficiary business before donation, and 88 employees was this number after the donation is provided.

Most businesses mention the fact that before receiving the donation, they worked by themselves or even with a maximum of two members of the family, and after the donation each business is required to increase the number of minimum 4 worker, or even in some cases 7 workers (nursery "Beqë Reqica "), 8 workers, the Furniture enterprises "Idrisi"; 10 employees, the "nursery of Godanci" or even 20 workers, "Sheep farm" in Mollopolc.

Increasing of production and reducing of production costs, as well as improvement of the conditions for development of the activity, have stated by all businesses, as an positive impact of the provided donation, followed by investment in new products, as for example, increasing of number of sheep, increasing of number of greenhouses, increase of the space for planting, etc.

It is worth noting also the business case of furnishing, for which businesses, the machinery offered as sophisticated machines for cutting the wood or even climbing them have influenced directly on producing faster and more qualitative products (Jashari, 2010\&Dugolli, 2011). 
Another one, is the case with enterprise for the cultivation of honey, where the owner notes that the provision of such assistance has contributed to the preservation of the bees, because before the donation it was a risk of their disappearance.

Based on all this we can conclude that the provided assitance was very helpful as in busines developement as well as in expanding its development, whether expansion into new products, as expansion of the stables (enterprises nr. 1), irrigation system (enterprise nr. 8), or as it is the example with the enterprises ", or as is the case with the company" Bardhi ", the owner of which emphasizes the fact that the before the donation, the milk they got from their livestock was sold daily while their main focus was on cattle growth. Now, the assistance provided has helped to increase profit by enabling the construction of a farm, and as a result now they are involved in the processing of milk and milk products (Aydin, 2010).

At the end, we can present some additional comments from the respondents that we get at the end of their interview, shows that all businesses are satisfied with the provided donation, which donation has affected on the production of more qualitative products, by effecting those in increasing of a reputation. The donation has hade effect for businesses on producing more qualitative product as well as expanding the market, within Kosovo, as well as outside it.

In general, the interviews show that the provided donation in equipment has had effect on development of their productive activity, which has also contributed to the growth of the welfare for families of the owners and the workers employed.

\section{Conclusion and implications}

The data presentation on this research shows that the overall cycle of the evaluation process can be summarized as a process of the planning of the evaluation plan, implementation of the plan, analysing and reporting the results of the evaluation.

With the evaluation plan is specifying the purpose of the evaluation on the basis of which developed evaluation questions and indicators (qualitative and/or quantitative), defined methodology and tools which will be used to implement the process, and identify key interest parties and sources of data collection needed for analysis from the results of the evaluation.

Each project is part of a specific program or strategy and the successful realization or his failure, gives positive or negative effects, based on the specific purpose.

Evaluation of a project is a necessary process to measure the effects of the project and the transfer of good practices in the future or needs for improvement for similar projects.

The realization of this research, as part of the Master's thesis, evaluation of concrete project "Supporting processing businesses", argues that the evaluation of the projects should be regarded as a necessary process of better management at all levels.

Being a project identified with the local economic development strategy for the municipality of Shtime, research results show that identification of real projects enables the successful implementation of the strategy.On the other hand, since the drafting of strategies for local economic development aims at creating a favorable environment for business, then the support of businesses through concrete projects strengthens the cooperation between local government and the business community. Cooperation with donors and the ability to withdraw funds, is another advantage, that municipality of Shtime, thanks to this project, has used to help processing businesses. Based on the indicators, sets for the evaluation of this project, we have come up with some results which give concrete answers to the evaluation questions, based on 
which we can conclude that:Provided support for businesses is considered very effective by the municipality as well as by the donor, due to which the beneficiary businesses still continue to develop successfully their business; The project has had a positive impact on local economic development for the municipality of Shtime, contributing to employment growth (50 workers), increasing the number of taxpayers $(30 \%)$ and improving the business structure in favor of production sector $(6.73 \%)$;

As a result of the provided support, all these 17 companies except increasing number of workers, have achieved good results in the increase of turnover $(50 \%)$ and profit $(30 \%)$, as well as expanding their market with new products.

At the end of this research and based on the results derived from the evaluation of the project, some recommendations should be proposed, which I think should be considered as necessary

Capacity building for the developing, monitoring and evaluation of strategies should be considered as a priority by our government institutions;

An office for monitoring and evaluation of projects in each ministry and municipality in Kosovo should be imperative, to follow so the realization of each program or strategy, part of which are projects

Municipality should have the plan for internal and external evaluation for strategic projects in the municipality, to increase cooperation with stakeholders as a good example for good practices to other municipalities through associations and business meetings.

\section{References}

American Evaluation Association (AEA) (2007). American Evaluation Association Guiding Principles for Evaluators. American Journal of Evaluation [Retrieved 11 February 2008]. 27(3), p. 293-294. Sage Publications. Available at: http://aje.sagepub.com

American Evaluation Association (AEA) (n.d). About Us. [Retrieved 10 March 2010]. Available at: http://www.eval.org/aboutus/organization/aboutus.asp;

Andrews, M., 1983. Evaluation: an essential process. Journal of Extension, [Retrieved 12 December 2010]. 21 (5), Available at: http://www.joe.org/joe/1983september/83-5-a1.pdf

Cunliffe, S., 2010. Monitoring and Evaluation as Practical Management Tools [Retrieved on: 17 August 2010]. Available at: http://archive.canada.icomos.org/bulletin/vol4_no3_cunliffe_e.html;

European Commission Liaison Office, ECLO. (2009). Final Report of the Poverty Alleviation in Marginalized Municipalities (PAMM) Project, Prishtinë: ECLO;

Guba, E.G. \& Lincoln, Y.S., 1989. Fourth Generation of Evaluation. Newbury Park, CA: Sage Publications;

International Fund for Agricultural Development (IFAD). 2002. A Guide for Project M\&E. IFAD: Office of Evaluation and Studies. [Retrieved 26 April 2010]; Available at: http://www.ifad.org/evaluation/guide/index.htm;

Noor, K. B. M., 2008. Case Study: A Strategic Research Methodology. American Journal of Applied Sciences, 5 (11), p.1602-1604. Science Publications. Available at: DOI: 10.3844/ajassp.2008.1602.1604; 
Lay, M. \& Papadopoulos, I., 2007. An exploration of Fourth Generation Evaluation in Practice. Evaluation; 13 (4), p.495-504. Sage Publication. Available at: DOI: $10.1177 / 1356389007082135$;

Leeuw, F.L.\& Furubo, J.E., 2008. Evaluation Systems: What Are They and Why Study Them. Evaluation, 14(2), p. 157-169. Sage Publication. Available at: DOI: $10.1177 / 1356389007087537$;

McDavid, 2005. Chapter 5: Applying qualitative evaluation methods. [Retrieved: 26 March 2010]. Sage publications. Available at: http://www.sagepub.com/upmdata/6195_Chapter_5_McDavid_I_Proof_3.pdf.;

McNamara, C., 2002. A Basic Guide to program Evaluation. [Retrieved 26 March 2010]. Available at:

https://www.tgci.com/sites/default/files/pdf/A\%20Basic\%20Guide\%20to\%20Program\%20 Evaluation_0.pdf;

Mustafa, M., 2009, Implementation of Local economic Development Strategy: Monitoring and Evaluation, Lecture authorized. Prishtinë: Riinvest;

Patton, M. Q., (2002), Qualitative research and evaluation methods. 3rd ed. Thousand Oaks, CA: Publication; ISBN: 9781412972123

Patton, M. Q., (1997), Utilization-Focused Evaluation. 4th ed. Thousand Oaks, CA: Sage Publication; ISBN: 9781412958615

Riinvest Institute for Development Research, (2002). 5th International Forum: Local Economic Development. Prishtinë: Riinvest;

Riinvest Institute for Development Research, (2007). Strategy for Local Economic Development 2007-2010: Municipality of Shtime. Prishtinë: Riinvest;

Riinvest Institute for Development Research, 2009. Evaluation report on: Implementation of Strategy for Local Economic Development 2007-2010: Municipality of Shtime. Prishtinë: Riinvest;

Roberts, K.,\&Coutts, J., 2007. Monitoring, Evaluation and Reporting of Extension. In APEN (Australasia Pacific Extension Network) NATIONAL FORUM'07. APEN: Australasian Extension Publication (AEP); Available at: http://www.apen.org.au/images/PDF\%20documents/APEN\%20Forum07\%20papers/Rob erts_Coutts__Methods_Monitoring_Evaluation_Reporting_of_Extension.pdf

Rossi, H. \& Freeman, E., 1993. Evaluation a Systematic Approach.5th ed. Newbury Park, CA: Sage publication; ISBN-13: 978-0803944589

Rumelt, R.P., 2000. Note on Strategy Evaluation - UCLA Anderson. [Retrieved 10 November 2010]. Available at: http://www.anderson.ucla.edu/faculty/dick.rumelt/Docs/Notes/StratEvaluation1999.pdf ;

Scriven M., 2001. An Overview of Evaluation Theories. Evaluation Journal of Australasia. [Retrieved 10 May 2010]; 1(2). Available at: http://www.aes.asn.au/publications/

Smith, J., 2004. Evaluating Local Economic Development Policies: Theory and Practice. [Retrieved 10 November 2010]. Available at: http://wwwpersonal.umich.edu/ econjeff/Papers/ledeval011204.pdf; 
Steel, M. S., 1970. Program Evaluation - A Broader Definition. Journal of Extension: Summer 1970, [Retrieved 12 December 2010]. Available at: http://www.joe.org/joe/1970summer/1970-2-a1.pdf;

Shaw, I.F., Greene, J.C. \& Mark, M.M., 2006. Hanbook of Evaluation: Policies, Programs and Practices. London: Sage Publication; ISBN: 9781446270554

The Global Fund (2009). Monitoring and Evaluation Concepts. [Retrieved 30 November 2010] 2009. Available at: www.theglobalfund.org/documents/me/ME_Concepts.pdf;

United Nation Development Program (UNDP). 2005. Assessment of Administrative Capacity in Kosovo. [Retrieved 22 July 2009]. Available at: http://www.ks.undp.org/repository/docs/Assessment\%20of\%20Administrative\%20Capaci ty\%20in\%20Kosovo\%20-\%20March\%202005.pdf;

United Nation Population Fund (UNFPA). 2004. Programme Manager's Planning, Monitoring \& Evaluation Toolkit. [Retrieved 05 October 2010]. Available at: http://www.unfpa.org/monitoring/toolkit.htm;

Weis, B.P., Berger, E., \& Hatcher, B., June 2008. A Guidebook to Strategy Evaluation: Evaluating Your City's Approach to Community Safety and Youth Violence Prevention. Los Angelos, CA: UCLA Southern California Injury Prevention Research Center;

William M.K. Trochim.2006. Introduction to Evaluation. [Retrieved 25 August 2010]. Available at: http://www.socialresearchmethods.net/kb/intreval.php;

World Bank Group. 2009. Local Economic Development. [Retrieved 20 April 2009]. (Updated on 2011) Available at: http://go.worldbank.org/V68WA64TF0; Zarinpoush F., 2006. Project Evaluation Guide for Nonprofit Organizations: Fundamental Methods and Steps for Conducting Project Evaluation. Toronto, Ontario, CA: Imagine Canada.

Top Achievement [Retrieved 20 April 2015] - Available at: http://topachievement.com/smart.html 